\title{
Current Preclinical Models of Ovarian Cancer
}

\author{
Elisabetta Kuhn ${ }^{1}$, Veronica Tisato ${ }^{1}$, Erika Rimondi ${ }^{2}$ and Paola Secchiero ${ }^{1}$ \\ ${ }^{1}$ Department of Morphology, Surgery and Experimental Medicine and LTTA Centre, University of Ferrara, Ferrara, Italy \\ ${ }^{2}$ Department of Life Sciences, University of Trieste, Trieste, Italy
}

"Corresponding author: Elisabetta Kuhn, Department of Morphology, Surgery and Experimental Medicine and LTTA Centre, University of Ferrara, Via Fossato di Mortara 66, 44121 Ferrara, Italy, Tel: 39-0532-455572; Fax: 39-0532-455950; E-mail: elisabettakuhn@hotmail.it, elisabetta.kuhn@unife.it

Received date: February 14, 2015, Accepted date: March 25, 2015, Published date: Mar 30, 2015

Copyright: () 2015 Kuhn E, et al. This is an open-access article distributed under the terms of the Creative Commons Attribution License, which permits unrestricted use, distribution, and reproduction in any medium, provided the original author and source are credited.

\begin{abstract}
Despite improvements in surgical and chemotherapeutic intervention of ovarian cancer over the recent decades, ovarian cancer remains the most lethal cancer in women. Notably, after an initial effective response to chemotherapeutic regimen, therapeutic resistance rises up leading to patient's death. This scenario highlights the urgent need to develop novel diagnostic and therapeutic strategies. Recently, several efforts to better understand the molecular bases of ovarian cancer using integrated multiplatform molecular profiling have revealed an intrinsic complexity and heterogeneity among ovarian cancers. Concurrently, a growing body of evidences implies fallopian tube epithelium as the likely site of origin of the majority of ovarian cancers. This fallopian tube hypothesis has shifted the attention of ovarian cancer research from the ovarian surface epithelium to the fallopian tube epithelium leading to adjustment of in vitro and in vivo ovarian cancer models. In this review article, we critically summarize recent advances in ovarian cancer preclinical models that have the potential to accelerate and facilitate the discovery of more effective biomarkers and target drugs for personalized cancer therapy.
\end{abstract}

Keywords: Ovarian cancer; Cell models; Mouse models; Xenografts; Fallopian tube

\section{Abbreviations: \\ EOC: Epithelial Ovarian Cancer; HGSC: High-Grade Serous Carcinoma}

\section{Introduction}

With approximately 22000 new cases diagnosed and 14000 deaths each year in United States, epithelial ovarian cancer (EOC) is the most lethal gynecological tumor worldwide [1]. High-grade serous carcinoma (HGSC) represents more than $70 \%$ of all EOCs and it is responsible of about $90 \%$ of EOC-related deaths. Recent clinicaltherapeutic innovations improved the disease free survival of patients with HGSC, without impacting on their overall mortality rate $[2,3]$. This is largely due to the complete darkness on HGSC carcinogenesis and, in particular, on the initial pathogenetic steps. As a consequence, HGSC is usually diagnosed at advanced stages, while precursor lesions remain elusive. The current therapeutic approach for HGSC contemplates surgery either anticipated or followed by the administration of platinum-taxane combined chemotherapy and is associated with good immediate response, but high rate of recurrence, locally and systemically. Notably, HGSC is insensitive to standard targeted therapy options, such as hormonal therapy and anti-HER2 agents, currently available for breast cancer patients [4,5]. Therefore, the most daunting challenge in ovarian cancer research is to develop new effective therapy to prevent and treat HGSC recurrence.

It is emerging that the five main histotypes of EOC (Table 1) must be considered as distinct diseases based on cell of origin, pathogenesis and molecular alterations [6-15]. In this respect, the effort of the scientific community to unravel the molecular alterations of HGSC (one of the first goal of The Cancer Genome Atlas consortium; TCGA), has allowed the identification of only few common somatic mutations, with the only exceptions of TP53 and BRCA1-2 genes, and none new common "druggable" candidate [16]. In addition, although the ovarian surface epithelium has been considered for long time the primary site of origin of all (both benign and malignant) epithelial ovarian tumors, the origin of EOC is still debated with an increasing consideration of extra-ovarian origin $[6,10,11]$. In particular, emerging evidences indicate the fallopian tube epithelium (FTE) and the endometrium as the sites of origin of ovarian HGSC and endometrioid/clear cell carcinoma, respectively [6]. Therefore, this new conceptual framework has shifted the attention of ovarian cancer research outside the ovary, from the ovarian surface epithelium to the FTE, renewing the interests in refining in vitro (cell cultures) and in vivo (animals) HGSC models (Figure 1). Experimental models used in ovarian cancer research substantially evolved over the last few years. As a general concept, the ability of the experimental models to accurately recapitulate the complexity of human cancer represents a critical issue in preclinical studies for drug discovery. The high rate of failure of novel cancer therapeutics during clinical trials highlights the inadequate predictability of laboratory cancer models currently available for preclinical studies.

In the present review, we attempt to summarize the current status of the art of in vitro and in vivo models of HGSC that better recapitulate various features of this cancer, focusing on their advantages and limitations. 
Citation: Kuhn E, Tisato V, Rimondi E, Secchiero P (2015) Current Preclinical Models of Ovarian Cancer. J Carcinog Mutagen 6: 220. doi:

Page 2 of 9

\begin{tabular}{|c|c|c|c|c|c|c|c|c|}
\hline Histotype & Grade & $\begin{array}{l}\text { Frequency } \\
\text { (\%) }\end{array}$ & Pathogenesis & $\begin{array}{l}\text { Cell of } \\
\text { origin }\end{array}$ & Precursor lesion & $\begin{array}{l}\text { Common } \\
\text { somatic } \\
\text { mutations }\end{array}$ & Type & References \\
\hline Brenner & Low-grade & $<1$ & Stepwise & FTE & Benign Brenner tumor & $\begin{array}{l}\text { KRAS } \\
\text { PIK3CA }\end{array}$ & 1 & {$[9,10]$} \\
\hline Mucinous & & 5 & $\begin{array}{l}\text { Stepwise/ } \\
\text { De novo }\end{array}$ & Unknown & $\begin{array}{l}\text { Adenoma } \\
\text { Mucinous Borderline tumor } \\
\text { Teratoma } \\
\text { Endometriosis }\end{array}$ & $\begin{array}{l}\text { BRAF } \\
\text { KRAS } \\
\text { RNF43 } \\
\text { TP53 }\end{array}$ & 1 & {$[6,12]$} \\
\hline Clear cell & & 5 & Stepwise & Endometrium & $\begin{array}{l}\text { Endometriosis } \\
\text { Borderline tumor } \\
\text { Adenofibroma }\end{array}$ & $\begin{array}{l}\text { ARID1A } \\
\text { KRAS } \\
\text { PIK3CA } \\
\text { PPP2R1A }\end{array}$ & 1 & {$[6,8]$} \\
\hline \multirow[t]{2}{*}{ Endometrioid } & Low-grade & 10 & Stepwise & Endometrium & $\begin{array}{l}\text { Endometriosis } \\
\text { Borderline tumor } \\
\text { Adenofibroma }\end{array}$ & $\begin{array}{l}\text { CTNNB1 } \\
\text { KRAS } \\
\text { MLH1 } \\
\text { MSH2 } \\
\text { MSH6 } \\
\text { PIK3CA } \\
\text { PTEN }\end{array}$ & I & {$[6,13]$} \\
\hline & High-grade & & Stepwise & Endometrium & $\begin{array}{l}\text { Endometriosis } \\
\text { Borderline tumor } \\
\text { Adenofibroma }\end{array}$ & $\begin{array}{l}\text { PPP2R1A } \\
\text { TP53 }\end{array}$ & II & {$[6,13]$} \\
\hline \multirow[t]{2}{*}{ Serous } & Low-grade & 5 & Stepwise & FTE & Serous borderline tumor & $\begin{array}{l}\text { BRAF } \\
\text { KRAS }\end{array}$ & 1 & {$[6,7]$} \\
\hline & High-grade & 70 & De novo & FTE & $\begin{array}{l}\text { Serous tubal intraepithelial } \\
\text { carcinoma }\end{array}$ & $\begin{array}{l}\text { BRCA1 } \\
\text { BRCA2 } \\
\text { TP53 }\end{array}$ & $\|$ & {$[6,11,16]$} \\
\hline
\end{tabular}

Table 1: Principal histotypes of ovarian epithelial tumors.

\section{Cell Models}

\section{Primary cell cultures}

Short-term cultures derived from freshly isolated cells or tissues, also designed primary cultures, have many important applications since they may recapitulate the pathophysiological system closely. However, primary cell cultures display common limiting characteristics: the slow growth capacity, the limited overall lifespan (i.e. they are not able of indefinite serial ex-vivo propagation) and the occurrence of changes and/or selection over passages, which hamper the system reproducibility. Other intrinsic limitations of primary cell culture system are that the tissue histology is lost along with endocrine, paracrine and neural regulators, gradients of nutrients and other factors. The cell cultures of interest to study HGSC biology are those derived from FTE as well as from ovarian cancers.

Primary cell cultures generated from fallopian tube epithelium: Human fallopian tube is gaining progressive attention, given its proposed role as the likely site of origin of HGSC. The FTE consists of a simple columnar epithelium composed of ciliated, secretory and intercalated cells [10]. During the last three decades methods for the in vitro expansion of FTE cells have been established [17-20]. The epithelial cells lining the inner surface of the human fallopian tube can be cultured in vitro and kept in culture for 6-8 weeks $[19,20]$. New epithelial cells appear after 2-3 days of primary cultures and small clusters after 7-10 days $[19,20]$. The plating and subculturing efficiency of FTE cells is very low, and the risk of contamination by fibroblasts is high $[19,20]$. Furthermore, serial cell passages result in loss of the ciliary markers of differentiation and in senescence over time [21]. The observed phenotypical plasticity depends strictly on culture conditions. As alternative experimental approach, cultures of FTE have been recently obtained seeding the isolated cells on the top of transwell filters coated with human placental collagen [22]. This model recapitulates faithfully the histological features of normal human FTE, preserving both morphological and phenotypical cell characteristics, although still characterized by finite proliferative capacity [23]. In order to overcome the proliferation limits, two research groups independently immortalized and transformed ex vivo normal human FTE cells by using human telomerase reverse transcriptase (hTERT) plus SV40 large $\mathrm{T}$ antigen and by ectopic expression of either oncogenic $\mathrm{H}-\mathrm{Ras}{ }^{\mathrm{V} 12}$ or c-Myc, alone or in conjunction with inhibition of $\mathrm{p} 53$ and $\mathrm{Rb}$ tumor suppressor pathways $[23,24]$. The transformed 
cells, injected in mice, produced tumor phenotypically and genotypically resembling human HGSC. In an analogous study, normal FTE cells were immortalized and transformed by ectopic expression of oncogenic H-Ras V12 [25]. These cells were tumorigenic when injected in immunocompromised mice, but at the histological examination the resulting tumors were mostly poorly differentiated mucinous adenocarcinoma mixed with undifferentiated carcinoma.

Primary cell cultures generated from ovarian cancer: Several methods for the isolation and culture of primary EOC cells, derived from either fresh solid tumor or ascites liquid, have been described $[26,27]$. Primary EOC cells usually adhere and tend to reach confluence quickly $[26,27]$. They can be kept in culture for 2-3 months before going into senescence. Short-term proliferative cells can be used for immediate experiments or cryostored, and represent a unique model suited for a multitude of applications [26,27]. Previous chemotherapy may affect cellularity and cell viability, therefore HGSC cells that have received recent chemotherapy have less growing efficiency in vitro $[26,27]$.

\section{Ovarian cancer cell lines}

Cancer cell lines are the model most commonly used in cancer research and their use has undoubtedly ameliorated our understanding of cancer biology [28,29]. An established cell line refers to a population of cells which has been serially passaged at least 60 times in vitro, and that is easily maintained in vitro and cultured for long periods of time. The Broad-Novartis Cancer Cell Line Encyclopedia and the TCGA projects together reported the genomic profiles of more than 1000 cell lines from various cancer lineages, including ovarian cancers [30,31]. Generally, cancer cell lines possess the same spectrum of genetic aberrations as primary tumors, although each cell line presents only a limited number of genetic aberrations, given that each cell line represents the intertumoral heterogeneity observed among primary tumors [30,31]. The cell immortalization leads to selection of a cell population phenotypically homogeneous and genetically clonal. Thus, a well-known caveat of cell lines is that they possess distinctive molecular genetics alterations driven by immortalization. It is therefore of extreme importance to confirm that these immortalized cell lines represent faithfully primary tumors with respect to original genomic alterations, since genomic alterations may result in molecular characteristics predictive of response (sensitivity vs resistance) to specific therapeutics. So far, numerous EOC cell lines have been established, and commercialized, but the histopathological origin of the most commonly used EOC cell lines, namely A2780, CAOV3, IGROV1, OVCAR-3 and SK-OV-3, remains unclear. As reported in a study performed by TCGA network investigators, a comparison between the molecular alterations of $47 \mathrm{EOC}$ cell lines and those of 316 primary HGSCs revealed that the EOC cell lines commonly used by scientists do not recapitulate the molecular alterations identified in primary HGSC [28]. This may explain the reason why in vitro studies using EOC cell lines usually fail to correctly predict clinical response and indicates that several EOC cell lines cannot be considered reliable in vitro HGSC models. In the same study [28], EOC cell lines were ranked based on the molecular similarity to primary HGSCs. The top ranking cell lines, characterized by major genomic similarity to primary HGSC are: KURAMOCHI, OVSAHO, SNU119, COV362 and OVCAR4 [28]. Therefore, these EOC cell lines can be considered the most suitable models for preclinical studies of HGSC.

\section{Ovarian cancer stem cells}

The cancer stem cell or tumor-initiating cell theory states the existence of a discrete population of tumor cells able to reconstitute the tumor upon implantation into recipient mice, by virtue of selfrenewal and multipotency abilities $[32,33]$. This theory holds relevant implications for cancer therapy since the cancer stem cells sit in a quiescence status that protects them against various chemotherapeutics. Hence, cancer stem cells are responsible for minimal residual disease and cancer recurrence [34].

Many studies have isolated, via fluorescent-activated cell sorting and characterized alleged human ovarian cancer stem cells from primary HGSC using surface antigens, such as ALDH1, CD44, CD133 and CD117, that define stem cell-like phenotype in other cancers [35-38]. The aforementioned isolated cells could fully recapitulate parental HGSC in xenografts and exhibited enhanced capacity to form spheroids and chemoresistance to conventional HGSC chemotherapeutics [35-38]. Interesting, Steffensen et al. found that HGSC patients with higher percentage of CD44 positive cancer stem cells had shorter progression-free survival [39]. Similarly, two other studies have reported that HGSC patients with increased ALDH1 expression showed poor prognosis [40,41]. In the same way, CD133 expression, alone or in combination with ALDH1, is a negative prognostic factor in HGSC patients [36,42]. Recently, Schwede et al. have identified a stem-cell line gene expression signature in a subset of HGSCs with higher propensity to form spheroids in vitro, to metastasize in vivo and with poorer prognosis [43]. Overall these findings support the existence of cancer stem cells in HGSC and emphasize the prognostic impact of cancer stem cells in HGSC patients.

Since HGSC relapse remains the major cause of treatment failure, targeting cancer stem cells offers an intriguing option to eradicate HGSC $[40,41]$. In the attempt to kill HGSC cancer stem cells, monoclonal antibodies and small molecules directed against cancer stem cell markers have been tested in HGSC preclinical models and patients. An inhibitor of CD117, Imatinib, is already used as the firstline chemotherapeutic drug for gastrointestinal stromal tumors and chronic myelogenous leukemia. Following a study reporting antiproliferative effects of Imatinib on EOC cell lines, Imantinib was tested in phase II clinical trials in patients with recurrent HGSC and demonstrated no efficacy [44-46]. In addition, preclinical studies have demonstrated the efficacy of both CD44/CD133 antibodies and ALDH1 inhibitor in EOC cell line xenografts [41,47-50]. The growing understanding of cancer stem cell biology unveiled alternative therapeutic approaches to eliminate cancer stem cells [51]. These latters set out to target features that contribute to cancer stem cell phenotype: cancer stem cells related pathways, ATP-binding cassette drug transporters and microenvironment (niche) [52]. Notably, our knowledge regarding EOC cancer stem cells mainly derives from either primary tumors or EOC cell lines [41].

\section{Animal Models}

\section{Spontaneous and carcinogen-induced models}

It is known that hens, some strains of mice, Wistar and SpragueDawley rats and the primate macaques develop ovarian tumors spontaneously [53-58]. In particular, the laying hen develops EOC that recapitulate the 4 major histotypes of women (serous, endometrioid, mucinous and clear cell) [53]. While these strains of mice and rats, 
develop a variety of tumors including tubular adenoma, papillary cystadenoma, adenocarcinoma, mesothelioma, germ cell tumor, granulosa cell tumor and sex-cord stromal tumor [54-57]. Finally, macaques spontaneously develop granulosa cell and sex-cord stromal tumors, but not epithelial tumors similarly to humans, even if they are anatomically more similar to humans [58]. In any case, these models have a relatively late-onset of tumor development and low incidence rate that make them useless for in vivo studies.

Since the late sixties, ovarian tumors have been induced in experimental animals by direct application of chemical carcinogens, although no chemical carcinogen has been consistently associated to EOC etiopathogenesis [59]. Ovarian tumorigenesis has been induced using many chemical carcinogens including 9:0-dimethyl-1:2benzanthrene, 7,12- dimethylbenz(a)anthracene, 20methylcholanthrene, 1,3-butadiene, formic acid 2- [4-(5-nitro-2furyl)-2-thiazolyl]hydrazide, a nitrofuran antibiotic, and N-methyl-N'nitrosourea, a direct-acting alkylating agent [59-65]. Interestingly, the initial lesions induced by these carcinogens, when analyzed, were ovarian surface epithelial proliferations, supporting the cancer origin from the ovarian surface epithelium. However, the induced carcinomas were composed by neoplastic cells resembling either endometrium or oviduct (that corresponds to the human FTE in mice), and were organized either in glandular or papillary structures similar to human endometrioid and ovarian serous carcinomas, respectively. Therefore, it remains controversial whether latter tumors originate from the ovarian surface epithelium that has undergone metaplastic transformation and morphologically resembles the oviduct or derive directly from the oviduct.

\section{Genetically engineered mouse models}

Genetically engineered mouse models for HGSC have been difficult to generate. Recently, the direct introduction of oncogenes and/or disruption of tumor suppressor genes into the oviduct allowed the generation of mouse models that recapitulate the new pathogenetic model of HGSC including the presence of lesions similar to serous tubal intraepithelial carcinoma, the putative precursor lesion $[66,67]$. Kim et al. developed an EOC mice model obtained by Dicer-Pten double knockout [68]. Clinically similar to human HGSC, this EOC arose from the oviduct, spread to the abdominal cavity and to the ovary, and led to ascites and death of $100 \%$ of mice [68]. Phenotypically and morphologically the developed tumors resemble HGSC, although differently they harbor unaltered p53 and altered Dicer [68]. Other investigators have generated de novo mouse model through the inactivation of Brca 1/2, Pten and Tp53 in fallopian tube secretory cells, miming the molecular alterations commonly observed in human HGSC [66]. More recently, Sherman-Baust et al. reported a transgenic mouse model that develops HGSC from serous tubal intraepithelial carcinoma through the inactivation of both p53 and $\mathrm{Rb}$ pathways, similarly to HGSC [67]. Notably, both latter mouse models recapitulated human HGSC from a clinical, histopathological, and genetic point of view $[66,67]$. Overall, all these genetically modified mouse models provide new evidence supporting the "fallopian tube hypothesis", i.e. the origin of HGSC from the fallopian tube (Figure 1). Therefore, they certainly offer a unique opportunity for the investigation of HGSC early events and carcinogenesis, and the exploration of new strategies of early detection, prevention and therapy. Moreover, this kind of syngeneic mouse models are optimal for the study of tumor microenvironment, angiogenesis, epithelialstromal interaction and antitumor immune mechanisms because preserve intact immune system. The major limitations of these models are that they are labor-intensive, expensive and time-consuming and do not fully replicate the genetic and epigenetic complexity of a spontaneous HGSC. Finally, being murine these tumors own speciesspecific characteristics and do not necessary behave as human HGSCs (Figure 2).
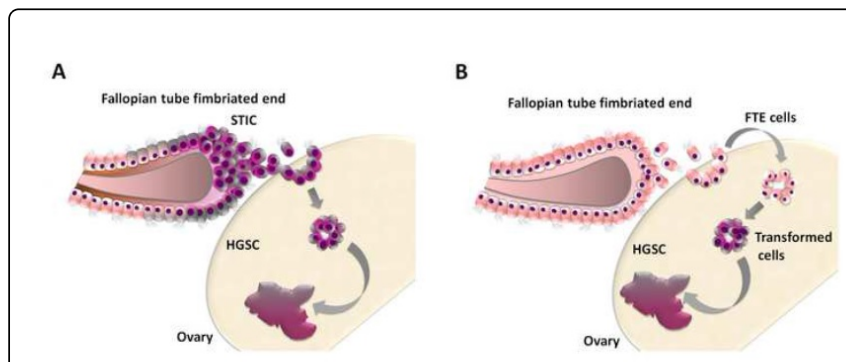

Figure 1: Fallopian tube hypothesis on the origin of high-grade serous carcinoma (HGSC). Fallopian tube epithelium (FTE) cells of the fimbriated ends undergo initial neoplastic transformation, becoming serous tubal intraepithelial carcinoma (STIC). STIC cells possess resistance to anoikis that favors settlement and invasion of the ovarian surface. The ovarian microenvironment, rich in hormonal and inflammatory factors, drives the full neoplastic transformation to invasive HGSC (A). Alternatively, the normal FTE cells are entrapped in the ovary favored by their anatomical proximity and physiological ovulation process. Entrapped FTE cells undergo progressive neoplastic transformation inside the ovary through the accumulation of molecular alterations (B).

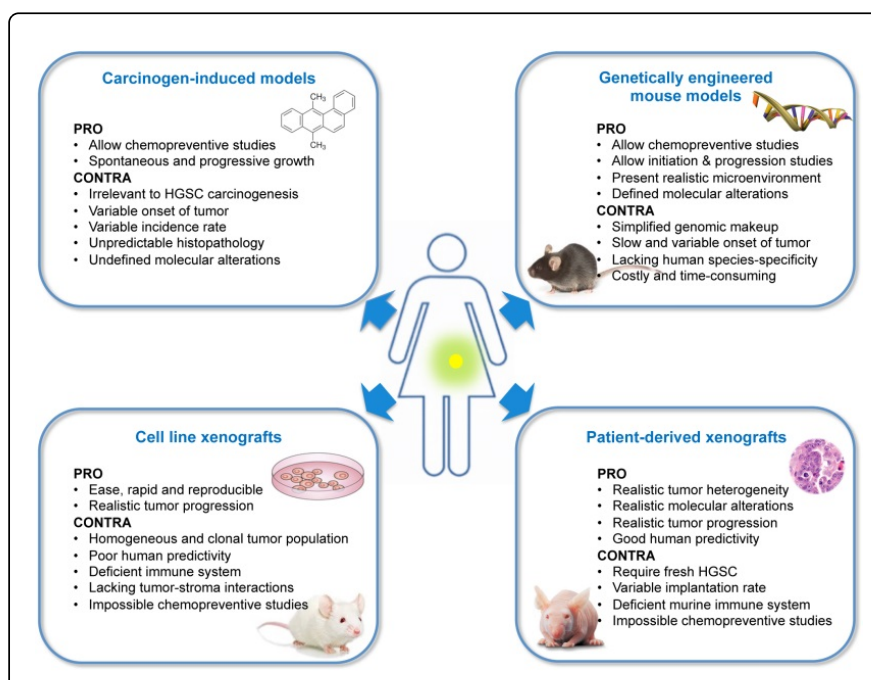

Figure 2: Comparison among the most common animal models used in ovarian cancer research. A summary of the major advantages (PRO) and limitations (CONTRA) of the different animal models used in ovarian cancer research is reported.

\section{Human xenograft models}

Heterotransplantation of cells is possible exclusively in immunounresponsive environment that prevents transplant rejection. However, engraftment rate of human tumor in immunocompromised rodents is low, likely due to residual adaptive and/or innate immunity, 
tumor intrinsic characteristics and experimental approches employed. Nowadays, human xenografts are generated by engrafting human tumor from either primary tumor or cancer cell line into immunodeficient mice, such as: i) athymic nude mice deficient in functional $\mathrm{T}$ lymphocytes, ii) severe combined immunodeficient (SCID) mice lacking both $\mathrm{B}$ and $\mathrm{T}$ lymphocytes, and iii) the nonobese diabetic (NOD)/SCID/IL2R $\gamma$ null mice which defect in adaptive and innate immunity due to lack of mature lymphocytes and natural killer $\mathrm{T}$ cells. The three main routes of implantation used for EOC xenografts are subcutaneous (ectopic), intraperitoneal and intrabursal (orthotopic) [69]. Subcutaneous implantation facilitates manipulation and serial measurements, but it does not recapitulate clinical tumor progression, since rarely malignant ascites and peritoneal carcinomatosis develop [70]. Intrabursal implantation consists in the injection of cells into the bursal membrane that envelops the mouse ovary and oviduct. This implantation site reproduces the physiological environment in which HGSC grows, so that tumor and ovary microenvironment can reciprocally interact and be modulated $[71,72]$. Therefore, intrabursal and intraperitoneal implantations best reproduce the clinical manifestations of human HGSC, recapitulating the early and late stage of the disease, respectively [69,71]. Moreover, the advent of noninvasive imaging instruments designed specifically for small animals allows monitoring of in vivo intraperitoneal tumor growth over time. Noteworthy, intraperitoneal and intrabursal sites require more time and major technical skill for successful implantation as compared to subcutaneous [70].

Cell line xenograft models: Despite many shortcomings, EOC cell line xenografts are the most utilized animal model in EOC research, providing a multifaceted toll to explore EOC biology and treatment [29,69-71,73]. Only selected EOC cell lines develop tumors when injected into immunocompromised mice, and the tumor engrafted usually acquires an indistinct undifferentiated morphology and displays complex genetic makeup since usually derives from patients with advanced stage $[72,74,75]$. The EOC cell line xenograft models commonly used are obtained by intraperitoneal injection of cell lines A2780, OVCAR-3 and SK-OV-3. Among these cell lines, OVCAR-3 genetically correlates to primary HGSC, whereas A2780 and SK-OV-3 do not harbor the typical genetic alterations of HGSC and are probably derived from endometrioid carcinoma [28]. As a consequence, such models do not accurately predict the clinical response of HGSC to novel anticancer agents, nor do they properly anticipate drug resistance and adverse reactions [4,45,76]. Nevertheless, some preclinical studies, using EOC cell line xenografts, correctly predicted anticancer drug response and effectively contributed to guide HGSC therapy. Specifically, antiangiogenic agents effectively reduced the formation of ascites in OVCAR-3 and SK-OV-3 cell line xenografts and in combination with paclitaxel synergically reduce tumor growth as well [77-79]. Clinical trials with bevacizumab, a monoclonal antibody to human vascular endothelial growth factor, confirmed its efficacy in HGSC patients, both as a single agent and in combination with paclitaxel $[80,81]$. Another example of successful use of cell line xenograft model includes the preclinical efficacy of PARP inhibitors in BRCA-deficient cells in vitro and in vivo $[82,83]$. PARP inhibitor monotherapy demonstrated favorable response in phase II/III clinical trials in patients with HGSC harboring $B R C A 1$ and $B R C A 2$ germline mutations, confirming the preclinical observations [84,85]. Latter studies demonstrated the ability of EOC cell line xenografts in parallel with in vitro studies in predicting drug efficacy, anticipating drug toxicity, identifying biomarkers related to drug response [79-82,86]. Therefore, the ability to successfully translate preclinical findings to
HGSC patients largely depends on the selection of appropriated EOC cell line or cell line panel, that must take into account the molecular drivers that better capture the underlying biology of primary HGSC and the likely key features of drug sensitivity.

In conclusion, the advantages of cell line xenografts include the rapidity of tumor formation, easy predictability, reproducibility, synchronization and the need of only few mice in drug response studies. On the other hand the primary limitations result from the use of EOC cell lines (above-mentioned) and immunocompromised mice, that are unable to fully represent the complex interaction between EOC and its microenvironment (immune system, stroma, inflammation, vasculature) (Figure 2).

Patient-derived murine xenograft models: The first patient-derived cancer xenograft (PDX) models were established in 1969, but only in the last decade its use became mainstream practice in cancer research [87]. In contrast to cell line xenografts, these emergent models feature direct transfer of tumor/ascites from patients into NOD/SCID mice, thus avoiding possible tissue culture artifacts. Mice bearing patient's ascites tumor usually do not survive after 8 weeks and necropsy findings show peritoneal effusion and multiple tumor nodules in the peritoneal wall and mesentery, a characteristic feature of advanced stage HGSC in patients. Of note, the morphological and molecular genetic features (TP53 mutation and DNA copy number alterations) of the PDX tumors are virtually indistinguishable from the tumor obtained from the patient, suggesting that the PDX model can faithfully simulate human HGSC [88-91]. Additional key characteristics of the PDX models in contrast with cell line xenografts are: i) the tumors in PDX maintain the human intratumoral stroma and the vascularization recapitulating the physiological microenvironment; ii) PDX xenografts allow the propagation and expansion of human tumors maintaining significant morphologic and genetic concordance with the parental primary HGSC over multiple murine generations. Thanks to their characteristics, PDX models are able to reflect/predict the therapeutic responsiveness observed in clinic, showing concordance with the original patient's treatment response [90,92], thus representing a unique opportunity toward personalized therapy for HGSC. However, some limitations affect this model. First, it requires a large amount of human fresh tumor and variable period of time to engraftment (2 to 4 months) [93]. Second, the tumor engraftment rate varies significantly in different studies depending on tumor characteristics, mice strain and implantation site [94]. Third, PDXs do not allow to study the role of immune system and, in the long run, also the tumor-stromal interactions since human stroma is eventually replaced by murine stroma [94]. Finally, the development, propagation and maintenance of PDX are timeconsuming, labor intensive and expensive.

Humanized-xenograft models: A critical shortcoming of xenografts is the lack of lymphocyte-mediated response as a consequence of immunodeficient mice used as recipients. Therefore, xenografts preclude the pathophysiological interaction between cancer cells and immune system that plays a key role in EOC initiation, progression and therapy response [95-98]. To overcome this issue, immunocompromised mice may be engrafted with peripheral CD34 positive blood cells, isolated from human umbilical cord or fetal liver, that are enriched for hematopoietic stem cells [99]. This strategy restores almost completely the human immune system in mice, renamed hematolymphoid humanized [100], and allows to study the immunological response to HGSC as well as the biology of HGSC preserving cancer immunoediting [101]. 
Another shortcoming of EOC xenografts is its inability to efficiently mimic epithelial/stromal interactions during tumor initiation due to the absence of normal human ovary. Dates back to 2001 the first study in which normal human ovarian tissue has been implanted into mice to test the morphological and functional preservation following cryostorage used to restore fertility in prepubertal children and women undergone to gonadotoxic treatment for cancer [102-104]. This approach can also have interesting applications in ovarian cancer research since allows to recreate in mice the human ovarian microenvironment where HGSC develops.

\section{Conclusions}

HGSC still represents an insurmountable challenge in gynecological oncology mainly because of late diagnosis and chemoresistance onset. Experimental cell and animal models are of pivotal importance to study human disease since allow: i) to understand the natural history and pathogenetic steps that lead to a fully developed disease; ii) to identify potential therapeutic targets; iii) to enable preclinical testing of novel therapeutics, alone or in combination with standard therapies.

To this day, we lack good inbred laboratory animals that develop HGSC. This is largely due to our limited understanding of the initiating factors that trigger HGSC. Moreover, anatomical, physiological and pathophysiological differences between animals and humans female reproductive system, including short lifespan, seasonal mouse reproduction, estrous cycle instead of menstrual cycle, and lack of menstruation may contribute to explain the difficulty in developing a representative laboratory animal model. It has to be underlined that the emerging "fallopian tube hypothesis" has given a new momentum to ovarian cancer research (Figure 1). As a consequence, new preclinical models, in which FTE cells undergo neoplastic transformation in vitro and in vivo, have been generated [23,24,66,67]. The use and spread of these pioneering models portend new opportunities to investigate the molecular and cellular alterations associated with HGSC initiation and may allow the development of novel prevention, early detection, and screening strategies. Nevertheless, EOC cell line xenografts are still commonly used in preclinical drug development $[80,81,84,85]$. Recent studies highlighted that, in order to increase the possibility to translate preclinical findings to clinic, the choice of EOC cell line (as biological surrogate of HGSC) should keep into account the molecular characteristics crucial to the biology of primary HGSC and to drug sensitivity[28].

As yet, the animal model that most closely mirrors human HGSC is PDX since it offers the relevant advantage of faithfully maintaining the characteristics of patients' parental tumor, preserving both stromal microenvironment and molecular alterations. Therefore, PDX holds the promise for personalized anticancer treatment and discovery of determinants of drug response [93]. In theory, PDXs allow for a rapid in vivo screening of targeted drugs and for the assessment of the chemosensitivity of patients' cancer. In particular, since different PDXs can be generated implanting tumor fragments obtained at different time points from the same patient, they potentially allow to capture the timeline of molecular alterations, i.e. tumor evolution, through exposure to therapy and development of chemoresistance, and, furthermore, to pre-test the response to new targeted therapies. Another prospective application of PDX models is represented by the screening of new anticancer compounds in a repertoire of HGSC PDX, that allows to capture HGSC interpatient heterogeneity [105]. Therefore, PDX provides a powerful experimental platform for treatment decision-making and for guiding targeted therapy in the clinic. In addition, it has been reported that PDX preserves cancer stem cells through multiple generations and chemotherapy, making PDX an excellent model to study the biology of cancer stem cells $[38,89]$. In this respect, the emergent picture of HGSC as a "cancer stem cell disease" is extremely appealing for its diagnostic and therapeutic implications, although further studies are necessary in order to better characterize stem cells in HGSC. In particular, the generation of stable models of HGSC stem cells seems an essential experimental tool needed to gain deeper knowledge and to allow the discovery of specific drug to target HGSC stem cells.

In the opening era of personalized medicine, the optimal choice of experimental cell and/or animal models remain fundamental to broad our knowledge on HGSC. For this purpose, experimental platforms must keep abreast of the ever-increasing molecular, pharmacological and clinical information from human disease in order to enhance their translational potential.

\section{References}

1. Siegel R, Ma J, Zou Z, Jemal A (2014) Cancer statistics, 2014. CA Cancer J Clin 64: 9-29.

2. Heintz AP, Odicino F, Maisonneuve P, Quinn MA, Benedet JL, et al. (2006) Carcinoma of the ovary. FIGO 26th Annual Report on the Results of Treatment in Gynecological Cancer. Int J Gynaecol Obstet 95 Suppl 1: S161-192.

3. Cho KR, Shih IeM (2009) Ovarian cancer. Annu Rev Pathol 4: 287-313.

4. Bookman MA, Darcy KM, Clarke-Pearson D, Boothby RA, Horowitz IR (2003) Evaluation of monoclonal humanized anti-HER2 antibody, trastuzumab, in patients with recurrent or refractory ovarian or primary peritoneal carcinoma with overexpression of HER2: a phase II trial of the Gynecologic Oncology Group. J Clin Oncol 21: 283-290.

5. Tropé C, Marth C, Kaern J (2000) Tamoxifen in the treatment of recurrent ovarian carcinoma. Eur J Cancer 36 Suppl 4: S59-61.

6. Kuhn E, Kurman RJ, Shih IM (2012) Ovarian Cancer Is an Imported Disease: Fact or Fiction? Curr Obstet Gynecol Rep 1: 1-9.

7. Jones S, Wang TL, Kurman RJ, Nakayama K, Velculescu VE, et al. (2012) Low-grade serous carcinomas of the ovary contain very few point mutations. J Pathol 226: 413-420.

8. Jones S, Wang TL, Shih IeM, Mao TL, Nakayama K, et al. (2010) Frequent mutations of chromatin remodeling gene ARID1A in ovarian clear cell carcinoma. Science 330: 228-231.

9. Kuhn E, Ayhan A, Shih IeM, Seidman JD, Kurman RJ (2014) The pathogenesis of atypical proliferative Brenner tumor: an immunohistochemical and molecular genetic analysis. Mod Pathol 27: 231-237.

10. Kuhn E, Ayhan A, Shih IeM, Seidman JD, Kurman RJ (2013) Ovarian Brenner tumour: a morphologic and immunohistochemical analysis suggesting an origin from fallopian tube epithelium. Eur J Cancer 49: 3839-3849.

11. Kuhn E, Kurman RJ, Vang R, Sehdev AS, Han G, et al. (2012) TP53 mutations in serous tubal intraepithelial carcinoma and concurrent pelvic high-grade serous carcinoma--evidence supporting the clonal relationship of the two lesions. J Pathol 226: 421-426.

12. Ryland GL, Hunter SM, Doyle MA, Rowley SM, Christie M, et al. (2013) RNF43 is a tumour suppressor gene mutated in mucinous tumours of the ovary. J Pathol 229: 469-476.

13. Madore J, Ren F, Filali-Mouhim A, Sanchez L, Kobel M, et al. (2010) Characterization of the molecular differences between ovarian endometrioid carcinoma and ovarian serous carcinoma. J Pathol 220: 392-400.

14. Kuhn E, Meeker AK, Visvanathan K, Gross AL, Wang TL, et al. (2011) Telomere length in different histologic types of ovarian carcinoma with emphasis on clear cell carcinoma. Mod Pathol 24: 1139-1145. 
15. Kuhn E, Meeker A, Wang TL, Sehdev AS, Kurman RJ, et al. (2010) Shortened telomeres in serous tubal intraepithelial carcinoma: an early event in ovarian high-grade serous carcinogenesis. Am J Surg Pathol 34: 829-836.

16. Cancer Genome Atlas Research Network (2011) Integrated genomic analyses of ovarian carcinoma. Nature 474: 609-615.

17. McComb P, Langley L, Villalon M, Verdugo P (1986) The oviductal cilia and Kartagener's syndrome. Fertil Steril 46: 412-416.

18. Ouhibi N, Menezo Y, Benet G, Nicollet B (1989) Culture of epithelial cells derived from the oviduct of different species. Hum Reprod 4: 229-235.

19. Henriksen T, Tanbo T, Abyholm T, Oppedal BR, Claussen OP, et al. (1990) Epithelial cells from human fallopian tube in culture. Hum Reprod 5: 25-31.

20. Kervancioglu ME, Saridogan E, Martin JE, Maguiness SD, Djahanbakhch O (1994) A simple technique for the long-term non-polarised and polarised culture of human fallopian tube epithelial cells. Biol Cell 82: 103-107.

21. Comer MT, Leese HJ, Southgate J (1998) Induction of a differentiated ciliated cell phenotype in primary cultures of Fallopian tube epithelium. Hum Reprod 13: 3114-3120.

22. Levanon K, Ng V, Piao HY, Zhang Y, Chang MC, et al. (2010) Primary ex vivo cultures of human fallopian tube epithelium as a model for serous ovarian carcinogenesis. Oncogene 29: 1103-1113.

23. Karst AM, Levanon K, Drapkin R (2011) Modeling high-grade serous ovarian carcinogenesis from the fallopian tube. Proc Natl Acad Sci U S A 108: 7547-7552.

24. Jazaeri AA, Bryant JL, Park H, Li H, Dahiya N, et al. (2011) Molecular requirements for transformation of fallopian tube epithelial cells into serous carcinoma. Neoplasia 13: 899-911.

25. Shan W, Mercado-Uribe I, Zhang J, Rosen D, Zhang S, et al. (2012) Mucinous adenocarcinoma developed from human fallopian tube epithelial cells through defined genetic modifications. Cell Cycle 11: 2107-2113.

26. Shepherd TG, Thériault BL, Campbell EJ, Nachtigal MW (2006) Primary culture of ovarian surface epithelial cells and ascites-derived ovarian cancer cells from patients. Nat Protoc 1: 2643-2649.

27. Thériault BL, Portelance L, Mes-Masson AM, Nachtigal MW (2013) Establishment of primary cultures from ovarian tumor tissue and ascites fluid. Methods Mol Biol 1049: 323-336.

28. Domcke S, Sinha R, Levine DA, Sander C, Schultz N (2013) Evaluating cell lines as tumour models by comparison of genomic profiles. Nat Commun 4: 2126 .

29. Indraccolo S, Tisato V, Agata S, Moserle L, Ferrari S, et al. (2006) Establishment and characterization of xenografts and cancer cell cultures derived from BRCA1 -/- epithelial ovarian cancers. Eur J Cancer 42: 1475-1483.

30. Barretina J, Caponigro G, Stransky N, Venkatesan K, Margolin AA, et al. (2012) The Cancer Cell Line Encyclopedia enables predictive modelling of anticancer drug sensitivity. Nature 483: 603-607.

31. Abaan OD, Polley EC, Davis SR, Zhu YJ, Bilke S, et al. (2013) The exomes of the NCI-60 panel: a genomic resource for cancer biology and systems pharmacology. Cancer Res 73: 4372-4382.

32. Bonnet D, Dick JE (1997) Human acute myeloid leukemia is organized as a hierarchy that originates from a primitive hematopoietic cell. Nat Med 3: 730-737.

33. Clevers $H$ (2011) The cancer stem cell: premises, promises and challenges. Nat Med 17: 313-319.

34. Wicha MS, Liu S, Dontu G (2006) Cancer stem cells: an old idea--a paradigm shift. Cancer Res 66: 1883-1890.

35. Baba T, Convery PA, Matsumura N, Whitaker RS, Kondoh E, et al. (2009) Epigenetic regulation of CD133 and tumorigenicity of CD133+ ovarian cancer cells. Oncogene 28: 209-218.

36. Silva IA, Bai S, McLean K, Yang K, Griffith K, et al. (2011) Aldehyde dehydrogenase in combination with CD133 defines angiogenic ovarian cancer stem cells that portend poor patient survival. Cancer Res 71: 3991-4001.

37. Alvero AB, Chen R, Fu HH, Montagna M, Schwartz PE, et al. (2009) Molecular phenotyping of human ovarian cancer stem cells unravels the mechanisms for repair and chemoresistance. Cell Cycle 8: 158-166.

38. Zhang S, Balch C, Chan MW, Lai HC, Matei D, et al. (2008) Identification and characterization of ovarian cancer-initiating cells from primary human tumors. Cancer Res 68: 4311-4320.

39. Steffensen KD, Alvero AB, Yang Y, Waldstrøm M, Hui P, et al. (2011) Prevalence of epithelial ovarian cancer stem cells correlates with recurrence in early-stage ovarian cancer. J Oncol 2011: 620523.

40. Deng S, Yang X, Lassus H, Liang S, Kaur S, et al. (2010) Distinct expression levels and patterns of stem cell marker, aldehyde dehydrogenase isoform 1 (ALDH1), in human epithelial cancers. PLoS One 5: e10277.

41. Landen CN Jr, Goodman B, Katre AA, Steg AD, Nick AM, et al. (2010) Targeting aldehyde dehydrogenase cancer stem cells in ovarian cancer. Mol Cancer Ther 9: 3186-3199.

42. Zhang J, Guo X, Chang DY, Rosen DG, Mercado-Uribe I, et al. (2012) CD133 expression associated with poor prognosis in ovarian cancer. Mod Pathol 25: 456-464.

43. Schwede M, Spentzos D, Bentink S, Hofmann O, Haibe-Kains B, et al. (2013) Stem cell-like gene expression in ovarian cancer predicts type II subtype and prognosis. PLoS One 8: e57799.

44. Matei D, Chang DD, Jeng MH (2004) Imatinib mesylate (Gleevec) inhibits ovarian cancer cell growth through a mechanism dependent on platelet-derived growth factor receptor alpha and Akt inactivation. Clin Cancer Res 10: 681-690.

45. Schilder RJ, Sill MW, Lee RB, Shaw TJ, Senterman MK, et al. (2008) Phase II evaluation of imatinib mesylate in the treatment of recurrent or persistent epithelial ovarian or primary peritoneal carcinoma: a Gynecologic Oncology Group Study. J Clin Oncol 26: 3418-3425.

46. Juretzka M, Hensley ML, Tew W, Konner J, Aghajanian C, et al. (2008) A phase 2 trial of oral imatinib in patients with epithelial ovarian, fallopian tube, or peritoneal carcinoma in second or greater remission. Eur J Gynaecol Oncol 29: 568-572.

47. Li SD, Howell SB (2010) CD44-targeted microparticles for delivery of cisplatin to peritoneal metastases. Mol Pharm 7: 280-290.

48. Lee SJ, Ghosh SC, Han HD, Stone RL, Bottsford-Miller J, et al. (2012) Metronomic activity of CD44-targeted hyaluronic acid-paclitaxel in ovarian carcinoma. Clin Cancer Res 18: 4114-4121.

49. Skubitz AP, Taras EP, Boylan KL, Waldron NN, Oh S, et al. (2013) Targeting CD133 in an in vivo ovarian cancer model reduces ovarian cancer progression. Gynecol Oncol 130: 579-587.

50. Du YR, Chen Y, Gao Y, Niu XL, Li YJ, et al. (2013) Effects and mechanisms of anti-CD44 monoclonal antibody A3D8 on proliferation and apoptosis of sphere-forming cells with stemness from human ovarian cancer. Int J Gynecol Cancer 23: 1367-1375.

51. Dawood S, Austin L, Cristofanilli M (2014) Cancer stem cells: implications for cancer therapy. Oncology (Williston Park) 28: 1101-1107, 1110.

52. Chen K, Huang YH, Chen JL (2013) Understanding and targeting cancer stem cells: therapeutic implications and challenges. Acta Pharmacol Sin 34: 732-740.

53. Barua A, Bitterman P, Abramowicz JS, Dirks AL, Bahr JM, et al. (2009) Histopathology of ovarian tumors in laying hens: a preclinical model of human ovarian cancer. Int J Gynecol Cancer 19: 531-539.

54. Tillmann T, Kamino K, Mohr U (2000) Incidence and spectrum of spontaneous neoplasms in male and female CBA/J mice. Exp Toxicol Pathol 52: 221-225.

55. Eppig JJ, Wigglesworth K, Varnum DS, Nadeau JH (1996) Genetic regulation of traits essential for spontaneous ovarian teratocarcinogenesis in strain LT/Sv mice: aberrant meiotic cell cycle, oocyte activation, and parthenogenetic development. Cancer Res 56: 5047-5054. 
56. Walsh KM, Poteracki J (1994) Spontaneous neoplasms in control Wistar rats. Fundam Appl Toxicol 22: 65-72.

57. Gregson RL, Lewis DJ, Abbott DP (1984) Spontaneous ovarian neoplasms of the laboratory rat. Vet Pathol 21: 292-299.

58. Cooper TK, Gabrielson KL (2007) Spontaneous lesions in the reproductive tract and mammary gland of female non-human primates. Birth Defects Res B Dev Reprod Toxicol 80: 149-170.

59. Krarup T (1969) Oocyte destruction and ovarian tumorigenesis after direct application of a chemical carcinogen (9:0-dimethyl-1:2benzanthrene) to the mouse ovary. Int J Cancer 4: 61-75.

60. Stewart SL, Querec TD, Ochman AR, Gruver BN, Bao R, et al. (2004) Characterization of a carcinogenesis rat model of ovarian preneoplasia and neoplasia. Cancer Res 64: 8177-8183.

61. Toth B (1970) Susceptibility of guinea pigs to chemical carcinogens: 7,12Dimethylbenz(a)anthracene and urethan. Cancer Res 30: 2583-2589.

62. Jacobs AJ, Curtis GL, Newland JR, Wilson RB, Ryan WL (1984) Chemical induction of ovarian epithelial carcinoma in mice. Gynecol Oncol 18: 177-180.

63. Nishida T, Sugiyama T, Kataoka A, Ushijima K, Yakushiji M (1998) Histologic characterization of rat ovarian carcinoma induced by intraovarian insertion of a 7,12-dimethylbenz[a]anthracene-coated suture: common epithelial tumors of the ovary in rats? Cancer 83: 965-970.

64. Tunca JC, Ertürk E, Ertürk E, Bryan GT (1985) Chemical induction of ovarian tumors in rats. Gynecol Oncol 21: 54-64.

65. Melnick RL, Huff JE, Roycroft JH, Chou BJ, Miller RA (1990) Inhalation toxicology and carcinogenicity of 1,3-butadiene in B6C3F1 mice following 65 weeks of exposure. Environ Health Perspect 86: 27-36.

66. Perets R, Wyant GA, Muto KW, Bijron JG, Poole BB, et al. (2013) Transformation of the fallopian tube secretory epithelium leads to high grade serous ovarian cancer in Brca;Tp53;Pten models. Cancer Cell 24: 751-765.

67. Sherman-Baust CA, Kuhn E, Valle BL, Shih Ie M, Kurman RJ, et al (2014) A genetically engineered ovarian cancer mouse model based on fallopian tube transformation mimics human high-grade serous carcinoma development. J Pathol 233: 228-237.

68. Kim J, Coffey DM, Creighton CJ, Yu Z, Hawkins SM, et al. (2012) Highgrade serous ovarian cancer arises from fallopian tube in a mouse model. Proc Natl Acad Sci U S A 109: 3921-3926.

69. Shaw TJ, Senterman MK, Dawson K, Crane CA, Vanderhyden BC (2004) Characterization of intraperitoneal, orthotopic, and metastatic xenograft models of human ovarian cancer. Mol Ther 10: 1032-1042.

70. Connolly DC, Hensley HH (2009) Xenograft and transgenic mouse models of epithelial ovarian cancer and non-invasive imaging modalities to monitor ovarian tumor growth in situ: applications in evaluating novel therapeutic agents. Curr Protoc Pharmacol 45: 14.12.1-14.12.26.

71. Fu X, Hoffman RM (1993) Human ovarian carcinoma metastatic models constructed in nude mice by orthotopic transplantation of histologicallyintact patient specimens. Anticancer Res 13: 283-286.

72. Kiguchi K, Kubota T, Aoki D, Udagawa Y, Yamanouchi S, et al. (1998) A patient-like orthotopic implantation nude mouse model of highly metastatic human ovarian cancer. Clin Exp Metastasis 16: 751-756.

73. Davy M, Mossige J, Johannessen JV (1977) Heterologous growth of human ovarian cancer. A new in vivo testing system. Acta Obstet Gynecol Scand 56: 55-59.

74. Verschraegen CF, Hu W, Du Y, Mendoza J, Early J, et al. (2003) Establishment and characterization of cancer cell cultures and xenografts derived from primary or metastatic Mullerian cancers. Clin Cancer Res 9: 845-852.

75. Schumacher U, Adam E, Horny HP, Dietl J (1996) Transplantation of a human ovarian cystadenocarcinoma into severe combined immunodeficient (SCID) mice--formation of metastases without significant alteration of the tumour cell phenotype. Int J Exp Pathol 77: 219-227.
76. Sabbatini P, Harter P, Scambia G, Sehouli J, Meier W, et al. (2013) Abagovomab as maintenance therapy in patients with epithelial ovarian cancer: a phase III trial of the AGO OVAR, COGI, GINECO, and GEICO--the MIMOSA study. J Clin Oncol 31: 1554-1561.

77. Mesiano S, Ferrara N, Jaffe RB (1998) Role of vascular endothelial growth factor in ovarian cancer: inhibition of ascites formation by immunoneutralization. Am J Pathol 153: 1249-1256.

78. Hu L, Hofmann J, Holash J, Yancopoulos GD, Sood AK, et al. (2005) Vascular endothelial growth factor trap combined with paclitaxel strikingly inhibits tumor and ascites, prolonging survival in a human ovarian cancer model. Clin Cancer Res 11: 6966-6971.

79. Hu L, Hofmann J, Zaloudek C, Ferrara N, Hamilton T, et al. (2002) Vascular endothelial growth factor immunoneutralization plus Paclitaxel markedly reduces tumor burden and ascites in athymic mouse model of ovarian cancer. Am J Pathol 161: 1917-1924.

80. Burger RA, Sill MW, Monk BJ, Greer BE, Sorosky JI (2007) Phase II trial of bevacizumab in persistent or recurrent epithelial ovarian cancer or primary peritoneal cancer: a Gynecologic Oncology Group Study. J Clin Oncol 25: 5165-5171.

81. Cannistra SA, Matulonis UA, Penson RT, Hambleton J, Dupont J, et al. (2007) Phase II study of bevacizumab in patients with platinum-resistant ovarian cancer or peritoneal serous cancer. J Clin Oncol 25: 5180-5186.

82. Farmer H, McCabe N, Lord CJ, Tutt AN, Johnson DA, et al. (2005) Targeting the DNA repair defect in BRCA mutant cells as a therapeutic strategy. Nature 434: 917-921.

83. Bryant HE, Schultz N, Thomas HD, Parker KM, Flower D, et al. (2005) Specific killing of BRCA2-deficient tumours with inhibitors of poly(ADP-ribose) polymerase. Nature 434: 913-917.

84. Fong PC, Boss DS, Yap TA, Tutt A, Wu P, et al. (2009) Inhibition of poly(ADP-ribose) polymerase in tumors from BRCA mutation carriers. N Engl J Med 361: 123-134.

85. Audeh MW, Carmichael J, Penson RT, Friedlander M, Powell B, et al. (2010) Oral poly(ADP-ribose) polymerase inhibitor olaparib in patients with BRCA1 or BRCA2 mutations and recurrent ovarian cancer: a proofof-concept trial. Lancet 376: 245-251.

86. Kim KJ, Li B, Winer J, Armanini M, Gillett N, et al. (1993) Inhibition of vascular endothelial growth factor-induced angiogenesis suppresses tumour growth in vivo. Nature 362: 841-844.

87. Rygaard J, Povsen CO (2007) Heterotransplantation of a human malignant tumour to "nude" mice. 1969. APMIS 115: 604-606.

88. Weroha SJ, Becker MA, Enderica-Gonzalez S, Harrington SC, Oberg AL, et al. (2014) Tumorgrafts as in vivo surrogates for women with ovarian cancer. Clin Cancer Res 20: 1288-1297.

89. Dobbin ZC, Katre AA, Steg AD, Erickson BK, Shah MM, et al. (2014) Using heterogeneity of the patient-derived xenograft model to identify the chemoresistant population in ovarian cancer. Oncotarget 5: 8750-8764.

90. Ricci F, Bizzaro F, Cesca M, Guffanti F, Ganzinelli M, et al. (2014) Patient-derived ovarian tumor xenografts recapitulate human clinicopathology and genetic alterations. Cancer Res 74: 6980-6990.

91. Elkas JC, Baldwin RL, Pegram M, Tseng Y, Slamon D, et al. (2002) A human ovarian carcinoma murine xenograft model useful for preclinical trials. Gynecol Oncol 87: 200-206.

92. Khabele D, Fadare O, Liu AY, Wilson AJ, Wass E, et al. (2012) An orthotopic model of platinum-sensitive high grade serous fallopian tube carcinoma. Int J Clin Exp Pathol 5: 37-45.

93. Hidalgo M, Bruckheimer E, Rajeshkumar NV, Garrido-Laguna I, De Oliveira E, et al. (2011) A pilot clinical study of treatment guided by personalized tumorgrafts in patients with advanced cancer. Mol Cancer Ther 10: 1311-1316.

94. Scott CL, Mackay HJ, Haluska P Jr (2014) Patient-derived xenograft models in gynecologic malignancies. Am Soc Clin Oncol Educ Book.

95. Zhang L, Conejo-Garcia JR, Katsaros D, Gimotty PA, Massobrio M, et al. (2003) Intratumoral $T$ cells, recurrence, and survival in epithelial ovarian cancer. N Engl J Med 348: 203-213. 
Citation: Kuhn E, Tisato V, Rimondi E, Secchiero P (2015) Current Preclinical Models of Ovarian Cancer. J Carcinog Mutagen 6: 220. doi:

96. Wei S, Kryczek I, Zou L, Daniel B, Cheng P, et al. (2005) Plasmacytoid dendritic cells induce $\mathrm{CD} 8+$ regulatory $\mathrm{T}$ cells in human ovarian carcinoma. Cancer Res 65: 5020-5026.

97. Scarlett UK, Rutkowski MR, Rauwerdink AM, Fields J, Escovar-Fadul X, et al. (2012) Ovarian cancer progression is controlled by phenotypic changes in dendritic cells. J Exp Med 209: 495-506.

98. Curiel TJ, Coukos G, Zou L, Alvarez X, Cheng P, et al. (2004) Specific recruitment of regulatory $\mathrm{T}$ cells in ovarian carcinoma fosters immune privilege and predicts reduced survival. Nat Med 10: 942-949.

99. Garcia S, Freitas AA (2012) Humanized mice: current states and perspectives. Immunol Lett 146: 1-7.

100. Ito $R$, Takahashi $T$, Katano I, Ito $M$ (2012) Current advances in humanized mouse models. Cell Mol Immunol 9: 208-214.

101. Schreiber RD, Old LJ, Smyth MJ (2011) Cancer immunoediting: integrating immunity's roles in cancer suppression and promotion. Science 331: 1565-1570
102. Gook DA, McCully BA, Edgar DH, McBain JC (2001) Development of antral follicles in human cryopreserved ovarian tissue following xenografting. Hum Reprod 16: 417-422.

103. Luyckx V, Scalercio S, Jadoul P, Amorim CA, Soares M, et al. (2013) Evaluation of cryopreserved ovarian tissue from prepubertal patients after long-term xenografting and exogenous stimulation. Fertil Steril 100: 1350-1357.

104. Sauvat F, Capito C, Sarnacki S, Poirot C, Bachelot A, et al. (2008) Immature cryopreserved ovary restores puberty and fertility in mice without alteration of epigenetic marks. PLoS One 3: e1972.

105. Kolfschoten GM, Pinedo HM, Scheffer PG, Schlüper HM, Erkelens CA, et al. (2000) Development of a panel of 15 human ovarian cancer xenografts for drug screening and determination of the role of the glutathione detoxification system. Gynecol Oncol 76: 362-368. 